\title{
PERFORMANCE AND EFFICIENCY IN INDIAN UNIVERSITIES
}

\author{
Geraint Johnes $^{1}$ \\ Jill Johnes ${ }^{2}$ \\ Swati Virmani ${ }^{3}$
}

1 Lancaster University Management
School
Lancaster LA1 4YX
United Kingdom
+44 1524594215
G.Johnes@lancaster.ac.uk
@geraintjohnes

1 Lancaster University Management

2 Huddersfield Business School University of Huddersfield Queensgate

Huddersfield HD1 3DH

United Kingdom

+44 1484422288

J.Johnes@hud.ac.uk

@JillJohnes

\author{
3 Leicester Castle Business Schoo \\ Dept of Economics \& Marketing \\ De Montfort University \\ Leicester LE1 9BH \\ United Kingdom \\ +44 1162506684 \\ Swati.virmani@dmu.ac.uk \\ @swativirmani8
}

\section{ABSTRACT}

While the evaluation of university efficiency has become commonplace in developed countries, exercises of this kind have rarely been conducted in the context of developing economies. We use frontier methods to analyse the determinants of costs in higher education institutions in India. Results obtained using the standard stochastic frontier model are compared with those from a latent class cost frontier model. Average incremental costs, returns to scale, and returns to scope are evaluated. Despite the relatively small size of average institution, we find that economies of scale are largely exhausted. The implications of various models for the evaluation of institution-level measures of efficiency are highlighted. The results differ in a number of respects from those obtained in more developed countries. Implications of the analysis for policy and practice are highlighted.

Keywords: stochastic frontier, latent class, efficiency, higher education, development JEL Classification: C29, L25, 121, 123, 125

The authors gratefully acknowledge, without implication, comments received from Samir Dani and from participants at the 7th International Workshop on Efficiency in Education, Health and Other Public Services, Universitat Internacional de Catalunya, Barcelona, 5-6 September 2019. 


\section{Introduction}

The importance of education as a driver of development has long been recognised (Barro, 1991; McMahon, 1998). This has informed government policy globally, with investment in education being prioritised especially in developing countries as one of the United Nations' Millennium Development Goals (Sachs, 2012). More recently, it has become apparent that the quality of education is of prime importance (Hanushek and Woessmann, 2011; Hanushek et al., 2013). From a public policy perspective, the efficiency with which educational institutions map inputs (such as expenditures) onto outputs (such as student achievement) is also important and has been the subject of much debate (Johnes, 2020).

In many developed economies, data on universities' inputs and outputs have been used to evaluate their efficiency and to encourage benchmarking as a means of improving performance. These studies have provided a rich source of knowledge about the nature of cost technologies in higher education, and in particular about the nature of economies of scale and of scope in this context. There has been much less work of this kind done on university systems in developing countries. This paper aims to redress this balance by studying data on universities in India. Specifically, we use frontier methods to analyse cost structures and efficiency, and pose the research question: do universities' cost structures in India follow similar patterns to those observed in developed economies? Our use of state-of-the-art stochastic frontier methods allows these cost structures to be analysed alongside the measurement of inter-institutional differences in technical efficiency, simultaneously making allowance for unobserved heterogeneity. The methodology simultaneously allows for inefficiency, stochastic errors and unobserved heterogeneity in cross section data and is therefore superior in this context to alternative options.

India provides a particularly interesting context in which to study university costs and efficiency within a developing economy. Over the last 20 years, there has been substantial growth in higher education in this country. ${ }^{1}$ The University Grants Commission identifies some 895 degree awarding institutions - up from 256 at the start of the century - and these serve almost 30 million students - up from 8 million at the start of the century. The institutions themselves are of various types. Some are specialist while others are comprehensive. Most receive government funding - either from the central government's Department of Higher Education (so-called 'central universities' and 'deemed to be' universities) or from state governments - but about one third of all institutions are private. Across the system as a whole, science and technology accounts for about one third of all student enrolments, arts accounts for a further one-third, and the remainder accounts for a variety of subject areas including social sciences and management. Universities offer degrees at all levels - bachelors, masters and doctorates. This being the case, even the more specialist institutions may be regarded as multi-product institutions.

This study addresses a significant gap in the current literature. In particular, it is anticipated that the application of the latent class stochastic frontier methodology to data from Indian higher education will reveal for the first time efficiency of university provision and the extent

\footnotetext{
${ }^{1}$ See https://www.ugc.ac.in/stats.aspx.
} 
to which expansion can be effected in existing institutions - important information for an economy where higher education provision is expanding at such a rate.

The paper proceeds as follows. Section 2 provides a brief overview of relevant literature. The paper involves a combination of several empirical methodologies and these are introduced in Section 3. Section 4 provides an introduction to the data set used in the paper, and Section 5 is the main analytical section which includes a detailed discussion of results. The paper ends with concluding remarks, which highlight the main implications for policy and practice, in Section 6.

\section{Literature Review}

In common with other exercises aimed at evaluating efficiency, analyses focused on the education sector are based on the pioneering work of Farrell (1957). Subsequent methodological advances, both using parametric statistical techniques and non-parametric methods grounded in linear programming, have allowed sophisticated applications that fully accommodate the complexity of producers that convert a multiplicity of inputs into a multiplicity of outputs. The availability of data on higher education institutions, their character as obviously multiproduct organisations (producing teaching and research across a wide range of disciplines), and the imperative of efficiency in organisations that often receive considerable public funding are all factors that have ensured the prominence given to studies of university efficiency in developed economies. Recent surveys of what is by now a very substantial literature include those of De Witte and López-Torres (2017) and Johnes (2020).

Outside the most advanced economies, less work has been done. One reason for this is that funding devoted to higher education has historically been comparatively small, given the relatively low participation rates in tertiary education in such countries. With the rapid growth of certain economies - the BRIC countries of Brazil, Russia, India and China are notable - the demand for higher education has increased quickly, and so ensuring the efficiency of higher education assumes increasing importance. In India, for example, the tertiary education enrolment rate rose from under $10 \%$ at the turn of the millennium to over $27 \%$ in $2017 .{ }^{2}$ Higher education is big business, and this is reflected in the growth in numbers reported previously.

This being the case, it is not surprising that the efficiency of provision in the higher education sector should increasingly have become a topic of interest. Indeed the cost of education in India has long been the topic of descriptive studies (see, for example, Tilak, 1988). Other early work by Sharma (1980) took a more analytical approach, modelling the relationship of costs in universities to outputs. In common with early work elsewhere (Verry and Layard, 1975; Verry and Davies, 1976) the models estimated in this study involve only a single output, but they are interesting in that they include quadratic specifications that allow some analysis of returns to scale and identification of a unit cost minimising level of output. Across a variety of model specifications, the cost minimising number of students is relatively small at around

\footnotetext{
${ }^{2}$ See https://data.worldbank.org/indicator/se.ter.enrr. To provide some context, and using the same source of data, this compares with China, for example, where the tertiary enrolment rate has risen from under $8 \%$ in 2000 to $51 \%$ in 2017.
} 
3100. More recent work, enabled (in parametric models) by the conceptual advances made by Baumol et al. (1982) and (in non-parametric applications) by the development of data envelopment analysis (DEA) by Charnes et al. (1978), allows a more refined understanding of the synergies that exist between the various outputs of higher education.

Kaur and Bhalla (2018) use frontier methods to examine the efficiency of 15 government colleges offering general degrees in Punjab state in India. Their model uses two inputs (government funding and academic staff numbers) and two outputs (undergraduate and postgraduate student enrolment) in a data envelopment analysis with variable returns to scale. Even within this relatively homogeneous group of institutions, they find considerable variation in the level of technical efficiency. Mean overall technical efficiency varies from 0.68 to 0.75 over the five years of the study, but the minimum efficiency observed is below 0.3. Another recent application of DEA (albeit one with weights restricted by an analytic hierarchy process) by Sahney and Thakkar (2016) use data on only four technical higher education institutes over a five year period, and find that overall technical efficiency varies from 0.54 to 100 over the 20 observations. Thus, despite the very small sample size, this study too finds that the level of efficiency varies markedly across institutions. Within a single institution, DEA has also been used to analyse the relative efficiency of academic departments in the Indian context (Tyagi et al., 2009). With only 19 departments in the university under study, average overall efficiency is unsurprisingly high at 0.87 , but there is a wide range in performance across departments with the least efficient having an efficiency score below 0.4 .

In other developing economies, analyses of the costs of higher education using stochastic frontier methods (Aigner et al., 1977) have already been undertaken. The most relevant of these in the context of the present study is a paper by Mamun (2011) that applies stochastic frontier methods to the analysis of costs in 18 institutions of higher education over a six year period in Bangladesh. He finds very high levels of efficiency - well over 0.9 for all universities in all years. Another important contribution that uses a similar multiproduct cost technology to that used in the present paper - but which unfortunately does not use frontier methods is that of Longlong et al, (2009) for China. This finds evidence of increasing product-specific returns to scale for research, but decreasing product-specific returns to scale for both undergraduate and postgraduate tuition, suggesting that research activity should be more concentrated. Also in the context of China, and with no accommodation of inefficiency in the estimation method (Cheng \& Wu 2008), there is evidence of diseconomies of scope in university outputs (undergraduate and postgraduate teaching and research). In additional papers relating to China, the focus is on distance education and international students respectively. Using non-frontier estimation methods, Li and Chen (2012) find product specific economies of scope for distance education and $\mathrm{Li}$ (2016) finds product specific economies of scope for international students, and indeed across the array of outputs including undergraduate and postgraduate students and research. The latter study also finds ray economies of scale and product specific economies of scale for undergraduates and international students. Evidence on economies of scale and scope from developing economies is therefore mixed, and this may partly be a consequence that not all such studies take into account the possible existence of inefficiency in the higher education system.

Other recent analyses of Indian universities have focused on their research performance (Marisha and Singh, 2017; Jalote et al., 2019) and their performance in attracting international 
students (Lavakare, 2017), itself an important source of funding that can enable further strengthening of the sector. While these are important dimensions of performance, in adopting a multiproduct approach to the analysis of costs, the analysis presented in the next section goes further, taking an holistic approach to the production of the multiplicity of outputs that characterise activity in the higher education sector.

\section{Methodology}

The analysis of costs in higher education institutions has drawn on several strands of the methodological literature. In particular, the estimation of cost functions involves the use of frontier methods, deriving from the early work of Aigner et al. (1977) in which costs, C, are modelled as a function of a vector of explanatory variables, $\mathbf{X}$, with a residual term that comprises two components - the normal white noise error term, $v$, and a one-sided component, $u$, (often half-normal) designed to capture variation across observations in efficiency. Hence

$C=X \beta+v+u$

The functional form may be straightforwardly linear, but, given the synergies that exist within complex higher education institutions, many studies draw upon the work of Baumol et al. (1982) to investigate returns to scale and scope. A quadratic functional form is therefore common in the empirical literature.

$\mathrm{C}=\beta_{0}+\sum_{i=1}^{m} \beta_{i} \mathrm{x}_{i}+1 / 2 \sum_{i=1}^{m} \sum_{j=1}^{m} \beta_{i, j} \mathrm{x}_{i} \mathrm{x}_{j}+\mathrm{v}+\mathrm{u}$

The one-sided residual in equations (1) and (2) can be evaluated at the level of each observation using the method provided by Jondrow et al. (1982). In addition to allowing the cost function to be evaluated in a manner consistent with theory - a cost function being an envelope around efficient points - therefore, the frontier method allows evaluation of the variation in efficiency across units of observation. Where the units of observation are, as is the case in the present application, public providers of services, this variation in efficiency is clearly something that is of great interest to government.

Equation (2) allows nonlinearities in the impact that a single output has on costs, and hence permits analysis of economies of scale. The interaction terms between the various outputs further allow analysis of economies of scope. Key to such analysis are the concepts of average incremental costs, and measures of product-specific and ray returns to scale and scope. Average incremental costs associated with production of the ith output type are defined as

$\operatorname{AIC}\left(y_{i}\right)=\left[C\left(y_{n}\right)-C\left(y_{n-i}\right)\right] / y_{i}$

Where $C\left(y_{n}\right)$ denotes the cost of producing all $n$ outputs and $C\left(y_{n-i}\right)$ is the cost of producing all outputs apart from the ith, and $y_{i}$ is the amount of the ith output produced. Product-specific returns to scale for the ith output are defined as the ratio of average incremental costs to marginal costs, such that 
Ray returns to scale are defined as

$\mathrm{S}_{\mathrm{R}}=\mathrm{C}(\mathrm{y}) / \sum_{i} \quad \mathrm{y}_{\mathrm{i}} \mathrm{C}_{\mathrm{i}}(\mathrm{y})$

and ray returns to scope are defined as

$\mathrm{S}_{\mathrm{C}}=\left[\begin{array}{ll}\sum_{i} & \mathrm{C}\left(\mathrm{y}_{\mathrm{i}}\right)-\mathrm{C}(\mathrm{y})\end{array}\right] / \mathrm{C}(\mathrm{y})$

The returns to scale measures are all analogous to the simple ratio of average cost to marginal cost that is frequently used to assess returns to scale in the single product case. As such, a measure in excess of unity indicates the presence of still unexploited economies of scale. If the measure is less than unity, however, economies of scale are exhausted. The measure used here for economies of scope has the property that positive values indicate that benefits arise from joint production.

Some recent investigations into the costs of higher education provision have used panel data methods, including random parameter stochastic frontier estimation. These allow for unobserved heterogeneity across universities. In the present context we can make only limited allowance for this, since we use cross-section data. But latent class models (Lazarsfeld and Henry, 1968) allow, on the basis of maximum likelihood, units of observation to be classified into a prescribed number of latent classes, and allow estimation of distinct vectors of coefficients to be undertaken for each of these classes. We explore the potential of such an approach later in the paper.

Taken together, the application of stochastic frontier methods to multi-product cost functions allows analysis of scale and scope economies in a context that fully accommodates the likelihood that producers (in this case universities) produce different products jointly because there are synergies involved in doing so, and moreover recognises the fact that cost functions envelop observations that might comprise inefficient producers. Furthermore, the latent class modelling that we undertake in the sequel serves both the purpose of accommodating unobserved heterogeneity and of providing a robustness check on earlier results. A recent survey that details the findings of numerous studies of this kind undertaken in developed economies is provided by Johnes (2020).

\section{Data}

The government of India's Ministry of Human Resource Development publishes the results of its National Institutional Ranking Framework (NIRF) online at https://www.nirfindia.org. The NIRF rankings of higher education institutions have been available since 2016, and are based on a wide variety of variables covering teaching and research outcomes, outreach, and reputational measures. (See Table A1 in the appendix for full details.) The data collection exercise involves a large number of colleges as well as degree-awarding institutions, and the total number of respondents to the exercise amounts to around 3500 . The rankings are constructed applying a set of prescribed weights to the various measures. Importantly for 
our purposes, the site reports data on all the key variables used in the construction of the ranking for the top 100 institutions. Of these, six undertake no undergraduate teaching, and we exclude these from the sample. In the present paper, we use data underpinning the 2019 rankings which report on statistics on teaching and research activities and on costs for the 2017-18 academic year.

The variables that we use include a measure of costs (total costs, including both current and capital expenditure ${ }^{3}$ ), undergraduate student numbers (on programmes ranging from two to six years in duration), and postgraduate student numbers (again on programmes that vary in duration, and including both taught and doctoral research programmes). As noted in the literature review, studies typically distinguish between levels of study - not least because class structure, teaching and learning methods, and the duration of courses differ between undergraduate and postgraduate stages. Since, in contrast to multi-input multi-output data envelopment analysis, the parametric stochastic frontier model requires a single dependent variable, our focus is on costs, which embody the expenditures associated with all inputs into the production process. This is in line with previous parametric studies on multi-product cost functions in higher education (Johnes, 2020).

The cost variable is measured in rupees (where one rupee is equivalent to about 1.5 US cents), and the undergraduate and postgraduate measures should be interpreted as total student numbers. We also include as an output a measure of research activity, based on a count of publications (a weighted average of data obtained from sources such as Scopus and Web of Science) per faculty member (where the number of faculty members is capped at the student roll divided by 15$)$; NIRF label this measure PU. ${ }^{4}$ It should be noted that this is more a reflection of reputation or productivity rather than gross output. Reputation measures have been used to reflect research output in a number of previous studies of higher education efficiency (Athanassopoulos and Shale 1997; Beasley 1990; 1995; Johnes et al 1993; Johnes 1996; Johnes and Yu 2008). We have repeated all of our analyses using alternative measures of costs (current costs only, current costs excluding expenditures on workshops) and research activity (a citations based measure, labelled QP by NIRF), but this makes little substantive difference to the results.

Table 1 provides descriptive statistics on the variables of interest in our study. The typical institution has around 5200 undergraduates and 3700 postgraduates. There is considerable variation in scale, however - the largest provider of undergraduate education has over 45000 undergraduates. Meanwhile the largest postgraduate institution has well over 20000 postgraduates. Research activity likewise varies considerably across the institutions in the

\footnotetext{
${ }^{3}$ These capital expenditures include investment in library resources and laboratory equipment, but do not include expenditure on land and building.

${ }^{4}$ Full details are at https://nirfcdn.azureedge.net/2019/framework/Overall.pdf. Note that there may be a bias in the distribution of publications across disciplines, and that this may lead to institutions that specialise in science being more likely than others to be included in the top 100 universities for which data are available. While it is unfortunate that the available data do not allow sample selection bias to be corrected for in our modelling, we note that the relatively small weight assigned to PU in the overall ranking (0.105) suggests that any bias is likely to be small.
} 
sample. The costs incurred by the average institution amount to a little over 3 billion rupees (slightly under $\$ 50$ million). ${ }^{5}$

Most of the data published by NIRF are supplied by the higher education institutions themselves and are subject only to limited auditing. Since the ultimate objective of the NIRF ranking is to influence the allocation of government funds, there may be some incentives for institutions to introduce inaccuracies into their reporting. Indeed, some observers have questioned the quality of data (Manuel, 2018) - noting in particular that, below the top 10 institutions, rankings lack stability from year to year (although this is not an uncommon feature of such rankings worldwide). It is prudent therefore to sense-check the data before proceeding further.

Figure 1 plots costs against undergraduate student numbers. The scatter shows a clear positive relationship. Observations are concentrated close to two or three rays from the origin, and this will, in specifications of our model reported later, motivate our decision to analyse the data using a latent class variant of the stochastic frontier. Unobserved heterogeneity across the institutions in our sample may explain different gradients on the relationship between scale and costs, and in the context of a cross-section data set the latent class approach is an appropriate means of addressing this issue. Figure 2 plots costs against postgraduate student numbers. Again there is a clear positive relationship, and again the observations are concentrated close to a multiplicity of distinct rays from the origin. While pointing to the desirability of allowing for unobserved heterogeneity, the data reported in Figures 1 and 2 do not alert us to any major concerns about the integrity of the data. Figure 3 gives the scatter plot of costs against research output. The relationship here is likewise positive, though the closeness of fit to a line through the data is lower than is the case for the student numbers data; this likely reflects heterogeneity across the institutions in the strength of their research missions.

\section{Analysis}

We begin by considering a straightforward linear model of costs. Table 2 provides coefficient estimates for a linear least squares model and for a stochastic (cost) frontier model that assumes a composite error made up of normal and half-normal components. In these equations, costs are measured in millions of rupees, and undergraduates and postgraduates are measured in thousands of students. The coefficients therefore suggest that the marginal cost of a postgraduate student is around 250000 rupees, while that of an undergraduate is about two thirds to three quarters as much. The most notable distinction between the OLS and stochastic frontier estimates is the magnitude of the constant term; the frontier is markedly shifted down from the cost curve obtained by best fit. This implies that there are substantial inefficiencies in provision, and justifies a frontier estimation approach.

These inefficiencies can be examined using the method of Jondrow et al. (1982), and the distribution of inefficiency scores is reported in Figure 4. This distribution is fairly even, with the exception of a large number of observations with very low efficiency scores. Not

\footnotetext{
${ }^{5}$ This compares with, for example, an average cost for US HEls of just under \$270million (Agasisti and Johnes 2015).
} 
surprisingly, given the larger sample size here, efficiency across this sample appears lower than the findings of previous studies (Kaur and Bhalla, 2018; Sahney and Thakkar, 2016). The group of universities with the lowest efficiencies is accounted for by institutions which are small in size; for such institutions, the highly negative intercept reported in Table 2 seems anomalous. We therefore consider that the results of this simple model need to be treated with considerable caution.

Indeed, the recent contributions of Agasisti and Johnes (2010, 2015), Johnes and Johnes $(2009,2016)$ and others suggest that simple models of the type considered above need refinement in any event in order to allow for unobserved heterogeneity across institutions. Such heterogeneity may be underpinned, for example, by differences in qualitative aspects of provision, subject mix (on which we have no data in the present exercise), or in labour market costs (which may be affected by local property prices). The low efficiency scores achieved in the simple model discussed above by small and specialist institutions is an example of this heterogeneity, and so motivates our adoption, in the remainder of this paper, of methods that finesse this problem. By comparing like with like within clusters of institutions (and hence avoiding comparisons of widely divergent institutions) the risk of making spurious comparisons of efficiency can be mitigated. While panel data methods provide a menu of choices for dealing with such unobserved heterogeneity (such as fixed effect or random effect methods), we are here dealing with a cross-section, and so we address the problem using latent class methods (Lazarsfeld and Henry, 1968). The results obtained by a latent class stochastic frontier analysis of the data (assuming two latent classes) are reported in Table 3. Some 69 institutions are allocated to latent class 1, with the remaining 25 institutions allocated to latent class 2 .

Several observations stand out from this table. First, the constant term differs markedly across the two latent classes. The descriptive statistics reported in Table 4 indicate that the institutions in latent class 1 are typically much larger, in terms of student numbers, than those in latent class 2; the higher intercept for the latter class seems reasonable given the nature of fixed costs that cannot, in these smaller institutions, be spread across large numbers of students. It is also possible that, in smaller institutions, greater reliance is placed on self-study methods, thus imposing higher fixed costs in the form of library resources, IT infrastructure and laboratories. Table 3 also shows higher marginal costs associated with the provision of the various outputs for institutions in latent class 1 compared with those in latent class 2 . Put simply, there is evidence here of considerable differences across institutions in the structure of costs.

The implications of the above analysis for efficiency can be observed in Figure 5 . The concentration of observations with very low efficiency scores is not removed altogether, but a much higher proportion of institutions, now that some accommodation has been made for unobserved heterogeneity, have relatively high efficiency scores - in Figure 5, some 27 institutions have scores above 0.8 , whereas the same is true of only 11 institutions in Figure 4. There is a marked difference in average efficiency between the two latent classes: universities in latent class 1 have an average efficiency score of 0.432, while those in latent class two have an average of 0.821 . Along with the preponderance of relatively low efficiency scores, the relatively large number of institutions in latent class 1 may indicate that there 
remains substantial heterogeneity across institutions within this class. We failed, however, to find a specification of the model that would allow the maximum likelihood algorithm to converge to a solution for any model involving more than two latent classes, and so were unable to explore this issue further. Qualitative analysis may be able to shed more light on this issue, but is beyond the scope of the present paper.

The allocation of institutions to one or the other latent class is done on the basis of maximum likelihood. The membership of each latent class is recorded in Table 5. Interestingly, latent class 2 consists mainly of engineering category institutions, and many of these universities offer a limited range of programmes and hence have lower total student numbers - as is also suggested by the descriptive statistics. The differences between the two latent classes can be examined further by way of a logit analysis that models assignment to one or the other latent class as a function of a variety of explanatory variables, with a dependent variable equal to one if the institution is assigned to latent class 2 . The explanatory variables include costs (as a measure of the size of institution), region (with West as the omitted category), a dummy variable for the capital city (Delhi), and a series of dummy variables identifying the type of institution (universities funded by central government, state government, or from private sources, institutions deemed to be universities despite not having formal university status, and the Indian institutes - public institutions of national importance, usually specialising in technology, and the excluded group of other institutions). Results are reported in Table 6. It is readily observed that few of the candidate explanatory variables achieve statistical significance. As noted in Table 4, larger institutions, as measured by costs, tend to be assigned to latent class 1 , the group with the lower average efficiency. Institutions located in the eastern region are relatively likely to be assigned to latent class 2, the group with the higher average efficiency. Many of these are located in West Bengal, a state that has pioneered modern education - founded in 1857, the University of Calcutta was the first multidisciplinary university in southern Asia. Indeed the efficiency of West Bengali universities is the subject of an interesting recent study by Jana et al. (2018). It may be the case that location in a region with a relatively long history of education provision advantages higher education institutions (in terms of the operations) in that region.

As noted above, the main driver for the classification of institutions into one or other latent class appears to be scale. Another method whereby we can analyse the effects of scale is to model a richer specification in which economies of scale and scope can be fully examined. Following Baumol et al. (1982), Cohn et al. (1989) and numerous others, we model the multiproduct cost function in quadratic form. The estimated parameters of the stochastic frontier, assuming that the composite error comprises normal and half-normal components, are reported in Table 7. Here costs are measured in millions of rupees and both undergraduate and postgraduate numbers in thousands of students. The results of a quadratic cost function are difficult to interpret, given the multiplicity of nonlinear terms in this functional form. The results provide reasonable estimates of average incremental costs, reported at mean values of the explanatory variables in Table 8. It is striking that the average incremental costs associated with postgraduates are somewhat lower than those attached to undergraduates; this is in marked contrast to the findings of studies undertaken in other countries, where the year round tuition, alongside smaller class sizes (and, in the case of doctoral students, individual supervision) for postgraduates tends to raise costs. The finding is also at variance with the results reported earlier in Tables 2 and 3 . As evidenced by the $z$ 
statistics reported in Table 7, the nonlinearity of the quadratic cost function is not precisely estimated. The confidence intervals around the average incremental costs reported in Table 8 are therefore likely to be wide, and the results in that table should not therefore be interpreted as strong evidence that the costs of delivering postgraduate education exceed those of delivering undergraduate education.

In Table 9, returns to scale and scope are reported. Product-specific economies of scale appear to be exhausted for both undergraduate and postgraduate tuition, while they remain unexhausted for research. This suggests that there may be opportunities to economise through increased concentration of research activity in fewer institutions. Ray economies of scale are exhausted, suggesting that at least some institutions are larger than is optimal. This aligns with the finding above that the latent class with the lower average efficiency is more likely to contain larger universities. It is worth interpreting these results, however, in the context of the finding that employing a quadratic functional form and allowing for inefficiency has a negative influence on conclusions regarding scale economies (Zhang and Worthington 2016).

The almost complete absence of scale economies in the average sized university recalls the finding, in early work, of Sharma (1980), which suggests that the optimal scale of operation of higher education institutions in India is unusually small by international standards. Note, however, that the results in Table 9 are obtained from a quadratic cost function estimated on all universities in the sample, while we know from the linear latent class models that there exist meaningful groupings of universities (that we have been unable to model separately in the quadratic specification). It may therefore be that economies of scale are exhausted for some universities at a considerably lower size than is the case for others, and that our analysis has failed to capture this nuance. Further research, using improved data that should become available in future, should explore this possibility.

Economies of scope are negative. This last finding is quite common in studies that employ a frontier methodology, since this tends to reduce the magnitude of the coefficient on the constant term representing fixed costs. However, this is contrary to the conclusions of Zhang and Worthington (2016) who find that studies using cross section data sets and/or based on developing country samples are more likely to find economies of scope.

In Figure 6 we report on the distribution of efficiency scores. This distribution is again surprisingly even, suggesting that substantial inefficiencies are observed in many institutions.

A natural further step in the analysis would be to estimate a latent cost stochastic frontier model of the quadratic cost function. Despite extensive experimentation, we have failed to estimate such a model - distinct latent classes cannot be identified once the richer quadratic functional form is employed. We intend to explore this further in future work employing panel data.

Studies of costs and efficiency of universities in developed economies have typically supported the finding that, for some outputs, economies of scale are unexhausted. The results reported above suggest that this might not be the case for teaching provision in India, 
at least for an institution of average size. The mix of specialised and comprehensive institutions studied here is not typical of the higher education scene in many developed economies, and further research could usefully focus on the issue of how scale economies are related to this profile. Another feature of our results that is unusual concerns how close are the estimated costs of study at, on the one hand, undergraduate and, on the other hand, postgraduate level. In the case of the nonlinear estimates, indeed, the average incremental costs of undergraduate study slightly exceed those of postgraduate work. Further inquiry is needed to establish what might explain this apparently idiosyncratic characteristic of higher education in India.

\section{Conclusion}

The emergence of data that allow analysis of cost structures in Indian higher education is welcome, and our paper is original in that it applies frontier estimation and a latent class approach to estimate multi-product cost functions for universities in India - a developing economy. Our conclusions are drawn from a variety of models and estimation approaches to ensure rigour. In many respects these cost structures resemble those that are familiar in other countries, but there are some idiosyncratic features of the Indian situation. Particularly striking amongst our findings is the apparent exhaustion of economies of scale in the tuition of both undergraduate and postgraduate students. This has a clear policy implication in that authorities wishing to expand the provision of higher education in India should, other things being equal, focus their efforts on growing smaller institutions rather than expanding those universities that are already operating at a scale above the optimum. If more expansion in student numbers is required than can be effected through growing the smallest universities, then establishing new institutions should be considered. However, given the small average size of Indian universities (in terms of student numbers) compared to universities in developed countries, a comparative study which investigates why economies of scale are exhausted sooner in India than other countries should be undertaken. Meanwhile, economies of scale remain unexhausted in the research domain, suggesting that further concentration of research activity could yield benefits. Again, there is a clear role for the authorities here in ensuring that incentives and reward for research activity are concentrated in the larger research institutions offering the greatest return on the investment in creating new knowledge. In common with other studies that use frontier methods to examine returns to scope, there appear to be no further synergies to be exploited; this finding should be treated with caution however, since many scope economies arise from low overhead costs on the frontier, and the reality is that institutions do not typically operate on this frontier.

Further policy implications may be found in the distributions of efficiency scores. Institutions that score low on efficiency may do so for a variety of reasons. The latent class method used in the present paper is unlikely fully to capture unobserved heterogeneity, and there may be legitimate reasons, albeit unexplained by our analysis, why costs might be higher in one institution than in others. Nevertheless, our analysis provides a starting point for investigating these differences, and the results indicate a relatively wide distribution of efficiency scores in comparison with those observed in other countries; this being so, the authorities might conclude that shortcomings in the efficiency of certain institutions should be addressed. 
Our results are of relevance not only to policy at national level, but also to practice at the level of the individual institution. The results reported above should be of interest to university managers seeking to benchmark their own institution's performance against that of comparator institutions. If, for example, the average costs of providing undergraduate tuition, postgraduate tuition and research substantially exceed those reported in Table 8 for a particular institution, then that institution's management might benefit from gaining an understanding of why this might be the case, and - if the cost gap cannot be justified - might with to take remedial action. In so doing, they might evaluate their own institution's position in the context of the returns to scale information provided in Table 9, and hence make cost saving decisions about the balance of provision within their institutions across the various spheres of activity.

Of course, our ability in the present paper to consider the important issue of unobserved heterogeneity has been limited by the fact that our data cover only one year. Latent class analysis mitigates this to some extent, but further analysis based on a panel of data should allow more detailed consideration of this issue in future work ${ }^{6}$ as more years of data become available. Further work should also seek to establish the robustness of results reported here to both alternative assumptions about the nature of the nonlinearity of the cost function, and to an expanded sample if future data sources permit.

\footnotetext{
${ }^{6}$ At present, inconsistencies across years in the definition of key variables in the NIRF data set, particularly those concerning research activity, mean that this is not possible.
} 
Table 1 Descriptive statistics

\begin{tabular}{|l|c|c|}
\hline variable & mean & standard deviation \\
\hline costs (billion rupees) & 3.17 & 2.51 \\
\hline undergraduate & 5209 & 6896 \\
\hline postgraduate & 3722 & 3563 \\
\hline research & 13.39 & 7.55 \\
\hline
\end{tabular}

Table 2 OLS and stochastic frontier estimates of the linear model

\begin{tabular}{|l|c|c|c|c|}
\hline & \multicolumn{2}{|c|}{ OLS } & \multicolumn{2}{c|}{ stochastic frontier } \\
\hline variable & coefficient & $\mathrm{t}$ & coefficient & $\mathrm{z}$ \\
\hline constant & 392.55 & 0.99 & -1053.03 & 2.89 \\
\hline undergraduate & 192.44 & 7.25 & 161.35 & 6.25 \\
\hline postgraduate & 252.76 & 4.75 & 252.02 & 6.85 \\
\hline research & 62.30 & 2.54 & 43.88 & 1.92 \\
\hline$\lambda$ & & & 4.35 & 3.31 \\
\hline$\sigma$ & & & 2352.87 & 141.53 \\
\hline & & & & \\
\hline $\mathrm{R}^{2}$ & 0.55 & & & \\
\hline
\end{tabular}

Table 3 Latent class stochastic frontier estimates of the linear model

\begin{tabular}{|l|c|c|c|c|}
\hline & \multicolumn{2}{|c|}{ latent class 1 } & \multicolumn{2}{c|}{ latent class 2 } \\
\hline variable & coefficient & $z$ & coefficient & $z$ \\
\hline constant & -1262.21 & 15.68 & 414.868 & 50.24 \\
\hline undergraduate & 173.51 & 2.10 & 72.3516 & 194.31 \\
\hline postgraduate & 205.59 & 7.03 & 85.1467 & 36.81 \\
\hline research & 92.37 & 1.44 & 14.5802 & 232.01 \\
\hline$\lambda$ & 2582.28 & 224.35 & 293.266 & 4.44 \\
\hline$\sigma$ & 1329.07 & 2449.35 & 1018.50 & 0.32 \\
\hline
\end{tabular}

Table 4 Descriptive statistics by latent class

\begin{tabular}{|l|c|c|c|c|}
\hline & \multicolumn{2}{|c|}{ latent class 1 } & \multicolumn{2}{c|}{ latent class 2 } \\
\hline variable & mean & $\begin{array}{c}\text { standard } \\
\text { deviation }\end{array}$ & mean & $\begin{array}{c}\text { standard } \\
\text { deviation }\end{array}$ \\
\hline $\begin{array}{l}\text { costs (billion } \\
\text { rupees) }\end{array}$ & 3.86 & 2.60 & 1.27 & 0.40 \\
\hline undergraduate & 5833 & 7671 & 3486 & 3654 \\
\hline postgraduate & 4221 & 3893 & 2342 & 18780 \\
\hline research & 12.98 & 8.35 & 14.51 & 4.65 \\
\hline
\end{tabular}




\begin{tabular}{|c|c|c|c|}
\hline \multicolumn{3}{|c|}{ latent class 1} & \multirow{2}{*}{$\begin{array}{c}\text { latent class } 2 \\
\text { Alagappa University }\end{array}$} \\
\hline Aligarh Muslim University & $\begin{array}{l}\text { Indian Institute of Technology (Indian School of } \\
\text { Mines) Dhanbad }\end{array}$ & National Institute of Technology Tiruchirappalli & \\
\hline Amity University & Indian Institute of Technology Bombay & NITTE & Anna University \\
\hline Amrita Vishwa Vidyapeetham & Indian Institute of Technology Delhi & North Eastern Hill University & Bharathiar University \\
\hline Anand Agricultural University & Indian Institute of Technology Gandhinagar & Osmania University & Birla Institute of Technology \\
\hline Andhra University & Indian Institute of Technology Guwahati & Panjab University & College of Engineering \\
\hline Banaras Hindu University & Indian Institute of Technology Hyderabad & Periyar University & Delhi Technological University \\
\hline Banasthali Vidyapith & Indian Institute of Technology Kanpur & Punjab Agricultural University & Guru Gobind Singh Indraprastha University \\
\hline Bharath Institute of Higher Education \& Research & Indian Institute of Technology Kharagpur & Sathyabama Institute of Science and Technology & $\begin{array}{l}\text { Indian Institute of Engineering Science and } \\
\text { Technology }\end{array}$ \\
\hline Bharathidasan University & Indian Institute of Technology Madras & Savitribai Phule Pune University & $\begin{array}{l}\text { Indian Institute of Science Education \& Research } \\
\text { Bhopal }\end{array}$ \\
\hline Bharati Vidyapeeth & Indian Institute of Technology Roorkee & Shiv Nadar University & $\begin{array}{l}\text { Indian Institute of Science Education \& Research } \\
\text { Kolkata }\end{array}$ \\
\hline Birla Institute of Technology \& Science & Jamia Hamdard & Siksha `O’ Anusandhan & $\begin{array}{l}\text { Indian Institute of Science Education \& Research } \\
\text { Mohali }\end{array}$ \\
\hline Calcutta University & Jamia Millia Islamia & $\begin{array}{l}\text { Sri Ramachandra Institute of Higher Education and } \\
\text { Research }\end{array}$ & Indian Institute of Technology Bhubaneswar \\
\hline Calicut University & Jawaharlal Nehru University & SRM Institute of Science and Technology & Indian Institute of Technology Mandi \\
\hline $\begin{array}{l}\text { Chaudhary Charan Singh Haryana Agricultural } \\
\text { University }\end{array}$ & JSS Academy of Higher Education and Research & $\begin{array}{l}\text { SVKM`s Narsee Monjee Institute of Management } \\
\text { Studies }\end{array}$ & Indian Institute of Technology Patna \\
\hline Cochin University of Science and Technology & Kalinga Institute of Industrial Technology & Symbiosis International & Institute of Chemical Technology \\
\hline Datta Meghe Institute of Medical Sciences & King George`s Medical University & Tamil Nadu Agricultural University & Jadavpur University \\
\hline Dr. D. Y. Patil Vidyapeeth & KLE Academy of Higher Education and Research & $\begin{array}{l}\text { Tamil Nadu Veterinary \& Animal Sciences } \\
\text { University }\end{array}$ & National Institute of Technology Durgapur \\
\hline G. B. Pant Universtiy of Agriculture and Technology & $\begin{array}{l}\text { Koneru Lakshmaiah Education Foundation } \\
\text { University (K L College of Engineering) }\end{array}$ & Tata Institute of Social Sciences & National Institute of Technology Warangal \\
\hline Gauhati University & Mahatma Gandhi University & $\begin{array}{l}\text { Thapar Institute of Engineering and Technology } \\
\text { (Deemed-to-be-university) }\end{array}$ & Pondicherry University \\
\hline Guru Nanak Dev University & Manipal Academy of Higher Education & University of Delhi & PSG College of Technology \\
\hline Indian Institute of Science & Mysore University & University of Kashmir & Sathyabama Institute of Science and Technology \\
\hline $\begin{array}{l}\text { Indian Institute of Science Education \& Research } \\
\text { Pune }\end{array}$ & National Institute of Technology Karnataka & Vellore Institute of Technology & $\begin{array}{l}\text { Shanmugha Arts Science Technology \& Research } \\
\text { Academy }\end{array}$ \\
\hline \multirow[t]{3}{*}{$\begin{array}{l}\text { Indian Institute of Technology (Banaras Hindu } \\
\text { University) Varanasi }\end{array}$} & National Institute of Technology Rourkela & Visva Bharati & Sri Sivasubramaniya Nadar College of Engineering \\
\hline & & & Sri Venkateswara University \\
\hline & & & Tezpur University \\
\hline
\end{tabular}


Table 6 Logit model of assignment to latent classes

\begin{tabular}{|l|c|c|}
\hline variable & coefficient & $\mathrm{z}$ \\
\hline constant & 3.30 & 1.89 \\
\hline costs & -0.003 & 3.54 \\
\hline east & 3.27 & 2.06 \\
\hline north & 0.69 & 0.52 \\
\hline north east & 1.02 & 0.40 \\
\hline south & 1.50 & 1.28 \\
\hline centrally funded & 0.34 & 0.17 \\
\hline state funded & -0.68 & 0.49 \\
\hline privately funded & -100.46 & 0.00 \\
\hline deemed university & -0.40 & 0.29 \\
\hline institute & -0.26 & 0.19 \\
\hline Delhi & 1.82 & 1.09 \\
\hline
\end{tabular}


Table 7 Stochastic frontier estimates of the quadratic model

\begin{tabular}{|l|c|c|}
\hline variable & coefficient & $\mathrm{z}$ \\
\hline constant & -361.43 & 0.52 \\
\hline undergraduate & 99.51 & 1.82 \\
\hline postgraduate & 17.37 & 0.06 \\
\hline research & 70.37 & 1.24 \\
\hline $\mathrm{ug}^{2}$ & 2.15 & 1.24 \\
\hline $\mathrm{pg}^{2}$ & 13.50 & 7.54 \\
\hline research $^{2}$ & -0.20 & 0.11 \\
\hline ug $\times$ pg & 11.55 & 1.84 \\
\hline ug $\times$ research & -4.03 & 1.06 \\
\hline $\mathrm{pg} \times$ research & -4.20 & 0.29 \\
\hline$\lambda$ & 2100.06 & 0.40 \\
\hline$\sigma$ & 2555.28 & 136.01 \\
\hline
\end{tabular}

Table 8 Average incremental costs (rupees)

\begin{tabular}{|c|c|c|}
\hline undergraduate & postgraduate & research \\
\hline 99777 & 71506 & 31092748 \\
\hline
\end{tabular}

Table 9 Returns to scale and scope

\begin{tabular}{|c|c|c|c|c|}
\hline \multicolumn{2}{|c|}{ product-specific returns to scale } & $\begin{array}{c}\text { ray returns } \\
\text { to scale }\end{array}$ & $\begin{array}{c}\text { returns to } \\
\text { scope }\end{array}$ \\
\hline undergraduate & postgraduate & research & & \\
\hline 0.899 & 0.587 & 1.094 & 0.784 & -0.412 \\
\hline
\end{tabular}


Figure 1 Scatterplot of costs $v$ undergraduate numbers

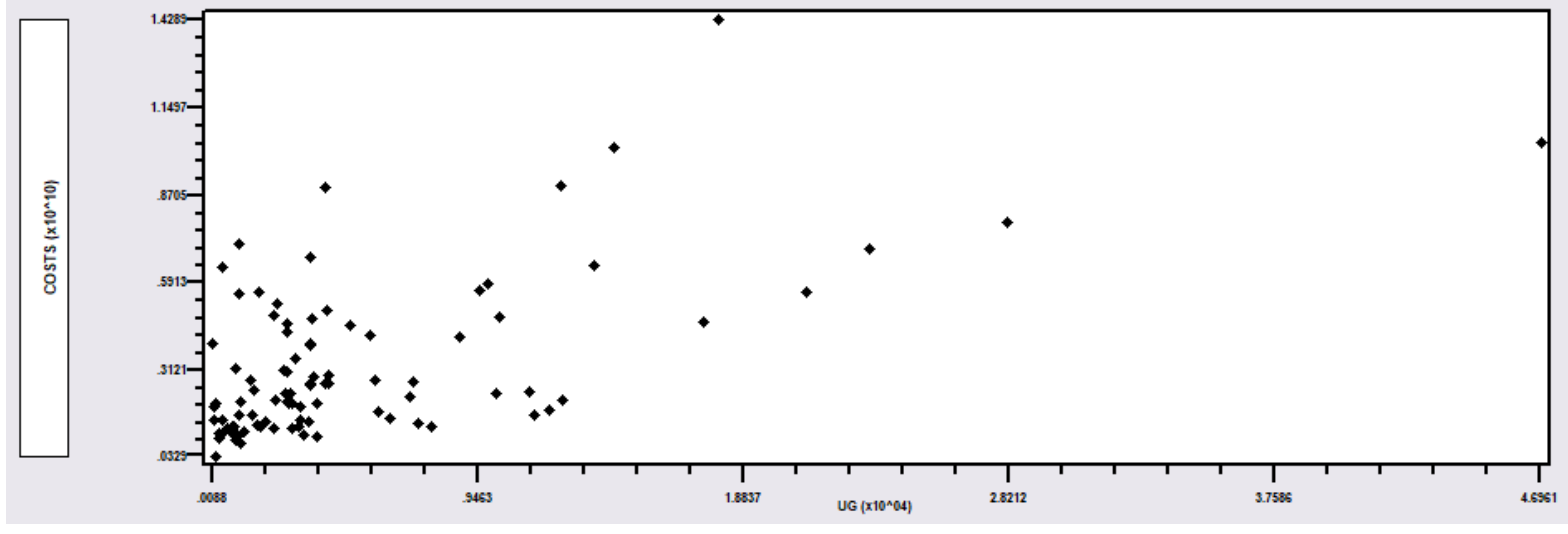

Figure 2 Scatterplot of costs v postgraduate numbers

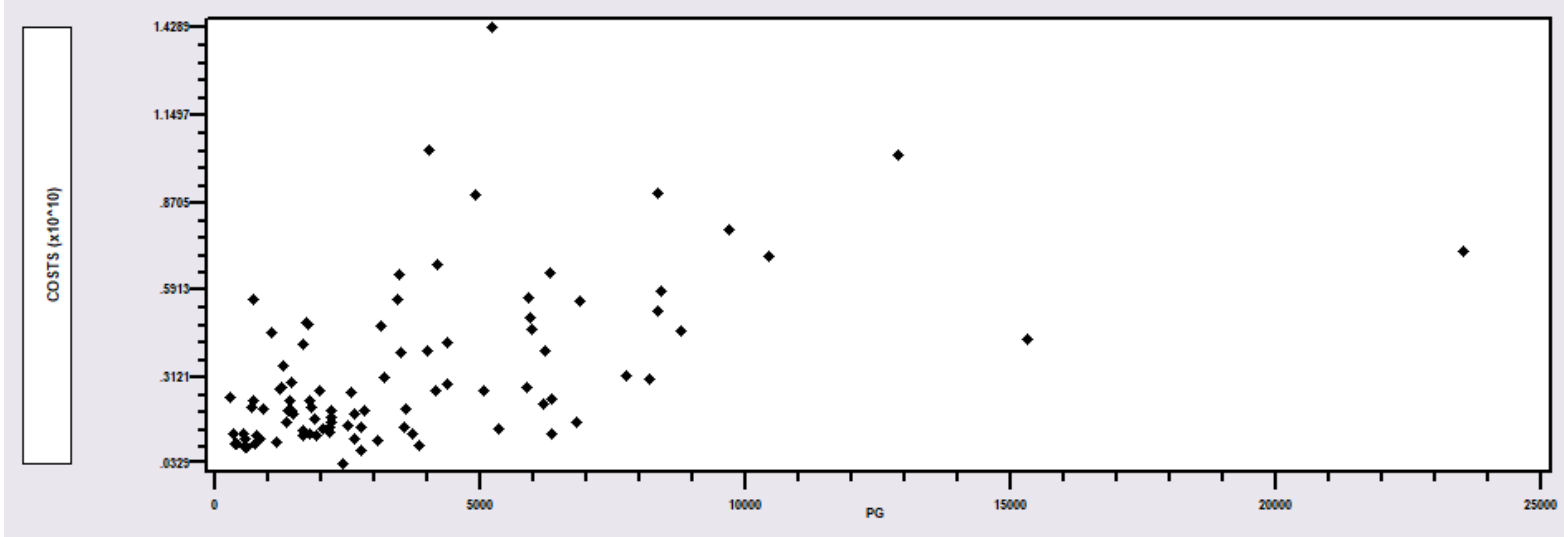

Figure 3 Scatterplot of costs v research output

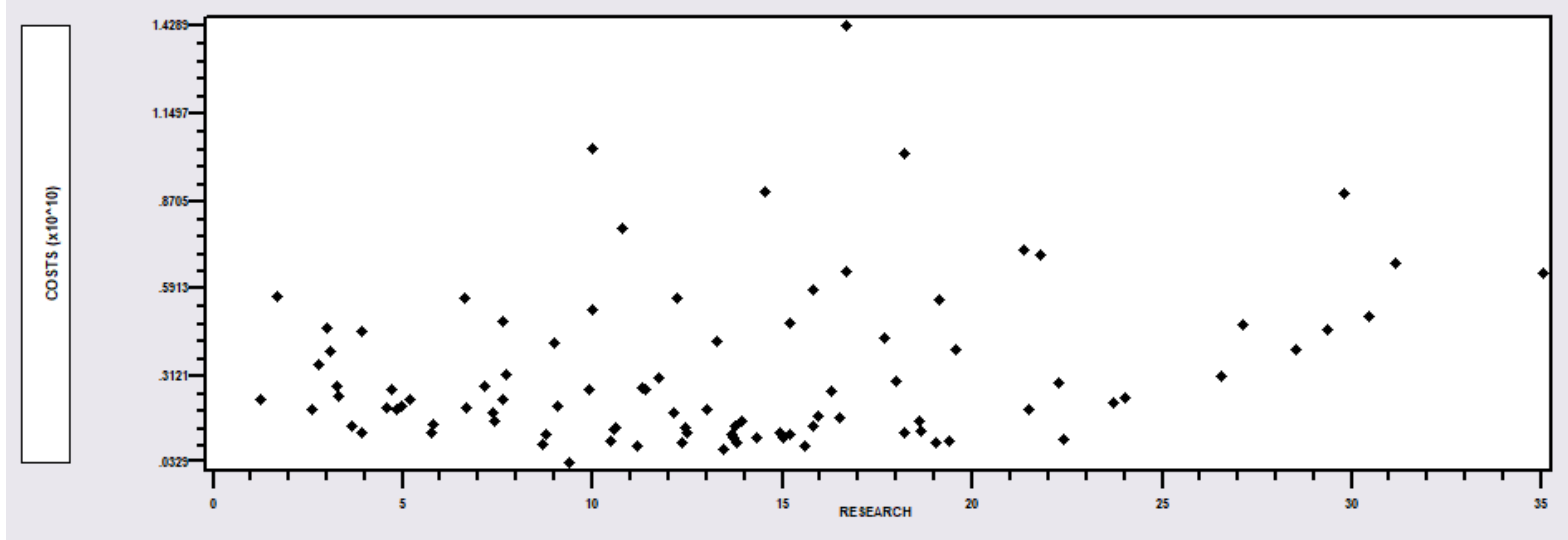


Figure 4 Histogram of efficiencies from the linear stochastic frontier model

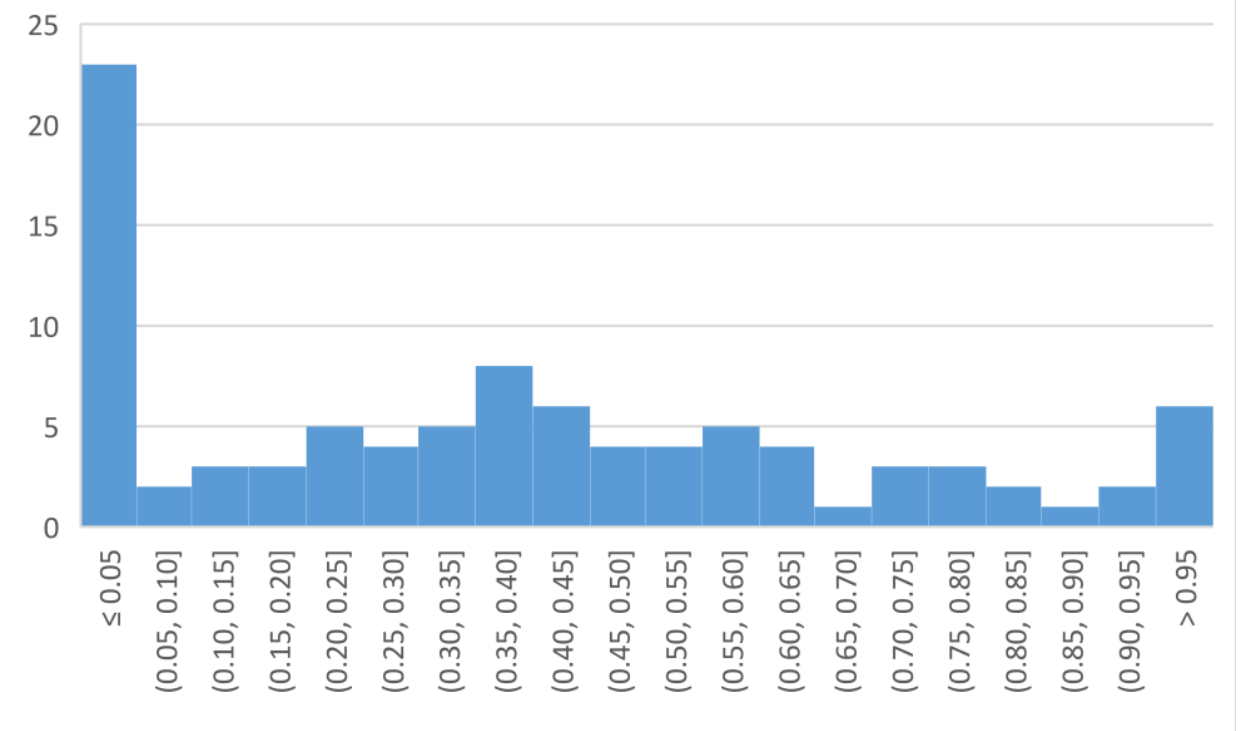

Figure 5 Histogram of efficiencies from the linear latent class stochastic frontier model

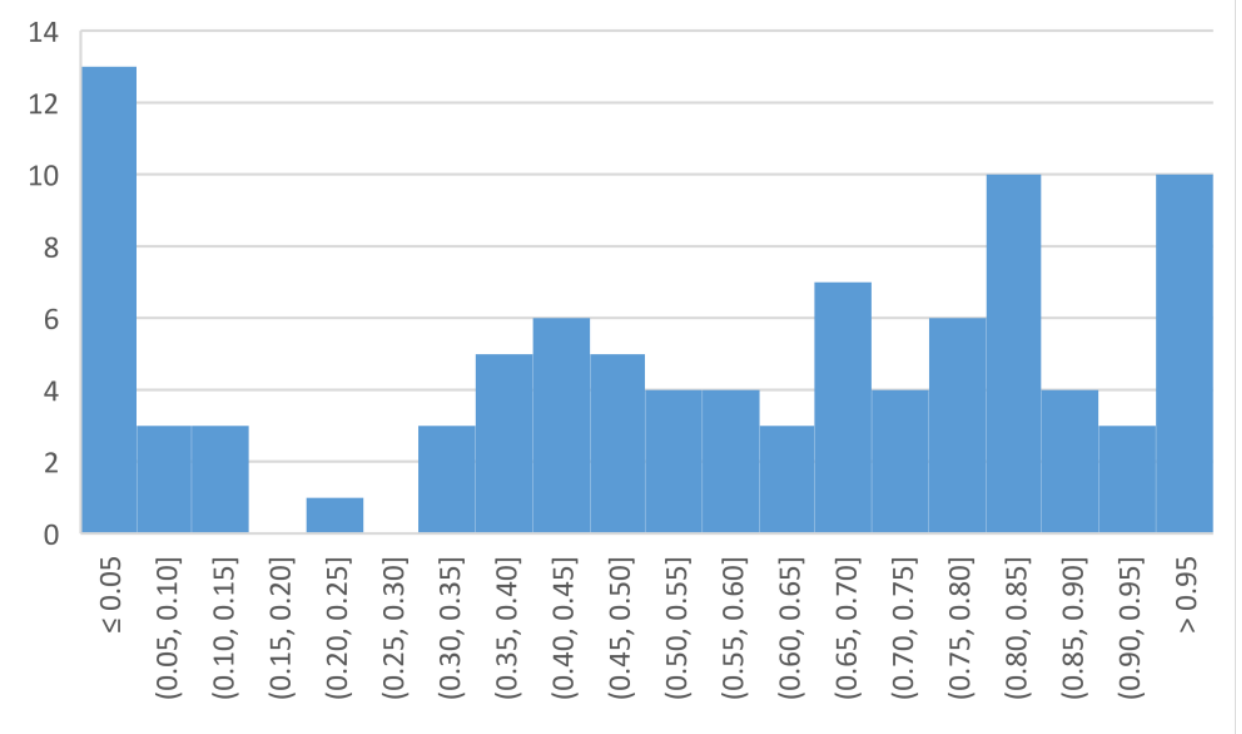


Figure 6 Histogram of efficiencies from the quadratic stochastic frontier model

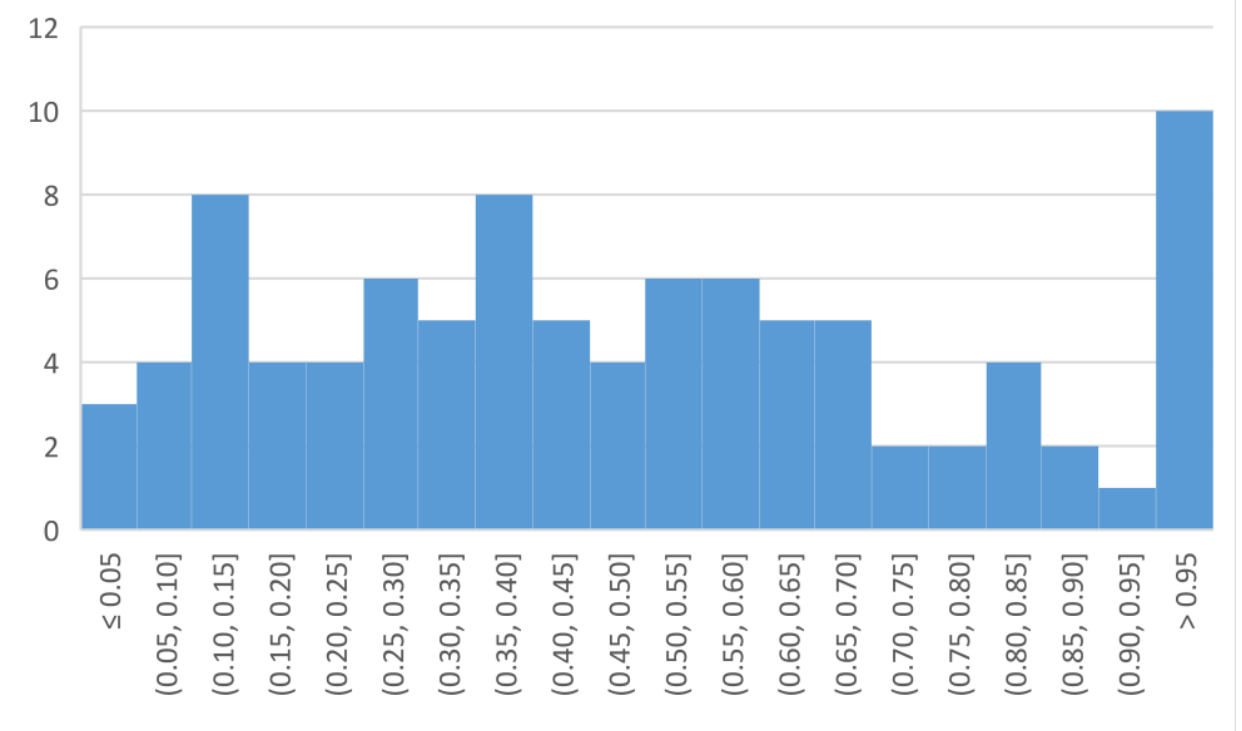


Agasisti, Tommaso and Geraint Johnes (2010) Heterogeneity and the evaluation of efficiency: the case of Italian universities, Applied Economics, 42, 1365-1376.

Agasisti, Tommaso and Geraint Johnes (2015) Efficiency, costs, rankings and heterogeneity: the case of US higher education, Studies in Higher Education, 40, 60-82.

Aigner, Dennis, Knox Lovell and Peter Schmidt (1977) Formulation and estimation of stochastic frontier production function models, Journal of Econometrics, 6, 21-37.

Athanassopulos, Antreas and Estelle Shale (1997) Assessing the comparative efficiency of higher education institutions in the UK by means of data envelopment analysis, Education Economics, 5(2), 117-135.

Barro, Robert J. (1991) Economic growth in a cross section of countries, Quarterly Journal of Economics, 106(2), 407-443.

Baumol, William J., John C. Panzar and Robert D. Willig (1982) Contestable markets and the theory of industry structure, Orlando: Harcourt Brace Jovanovich.

Beasley, John E. (1990) Comparing university departments, Omega, 18(2), 171-183.

Beasley, John E. (1995) Determining teaching and research efficiencies, Journal of the Operational Research Society, 46(4), 441-452.

Charnes, Abraham, William Cooper and Eduardo Rhodes (1978) Measuring the efficiency of decision making units, European Journal of Operational Research, 2, 429-444.

Cheng, Gang and Keming Wu (2008) The internal efficiency in higher education: An analysis based on economies of scope, Frontiers of Education in China, 3(1), 79-96.

Cohn, Elchanan, Sherrie L.W. Rhine and Maria C. Santos (1989) Institutions of higher education as multiproduct firms: economies of scale and scope, Review of Economics and Statistics, 71, 284-290.

De Witte, Kristof and Laura López-Torres (2017) Efficiency in education: a review of literature and a way forward, Journal of the Operational Research Society, 339-363.

Farrell, Michael (1957) The measurement of productive efficiency, Journal of the Royal Statistical Society, 120, 253-290.

Hanushek, Eric A., Susanne Link and Ludger Woessmann (2013) Does school autonomy make sense everywhere? Panel estimates from PISA, Journal of Development Economics, 104, 212232.

Hanushek, Eric A. and Ludger Woessmann (2011) The economics of international differences in educational achievement, in Eric Hanushek, Stephen Machin and Ludgetr Woessmann (eds) Handbook of the Economics of Education, volume 3, Amsterdam: North Holland. 
Jalote, Pankaj, Bijendra Nath Jain and Sudhir Sopory (2019) Classification for research universities in India, Higher Education, forthcoming.

Jana, Sebak Kumar, Adwaita Maiti and Pranjit Paul (2018) Efficiency of higher education institutes: a study on some universities in West Bengal, India, International Journal of Research and Analytical Reviews, 5(4), 548-554.

Johnes, Geraint (2020) Economic approaches to school efficiency, in Steve Bradley and Colin Green (eds) The Economics of Education: a Comprehensive Overview, $2^{\text {nd }}$ edition, Amsterdam: Academic Press / Elsevier, 479-489.

Johnes, Geraint and Jill Johnes (2009) Higher education institutions' costs and efficiency: taking the decomposition a further step, Economics of Education Review, 28, 107-113.

Johnes, Geraint and Jill Johnes (2016) Costs, efficiency, and economies of scale and scope in the English higher education sector, Oxford Review of Economic Policy, 32 (4), 596-614.

Johnes, Jill, Jim Taylor and Brian Francis (1993) The research performance of UK universities: a statistical analysis of the results of the 1989 research selectivity exercise, Journal of the Royal Statistical Society Series A, 156(2), 271-286.

Johnes, Jill (1996) Performance assessment in higher education in Britain, European Journal of Operational Research, 89, 18-33.

Johnes, Jill and Li Yu (2008) Measuring the research performance of Chinese higher education institutions using data envelopment analysis, China Economic Review, 19(4), 679-696.

Jondrow, James, C.A. Knox Lovell, Ivan S. Materov and Peter Schmidt (1982) On the estimation of technical inefficiency in the stochastic frontier production function model, Journal of Econometrics, 19, 233-238.

Kaur, Harpreet and Gurwinder Singh Bhalla (2018) Evaluating the resource use efficiency of government colleges in Punjab (India): a data envelopment analysis, International Journal of Law and Management, 60(3), 804-813.

Lavakare, Prabhakar J. (2017) When will Indian universities open their doors to international students?, Current Science, 113(9), 1653-1654.

Lazarsfeld, Paul F. and Neil W. Henry (1968) Latent Structure Analysis, Boston: Houghton Mifflin.

Li, Fengliang and Xinlei Chen (2012) Economies of scope in distance education: The case of Chinese research universities, International Review of Research in Open and Distance Learning, 13(3), 117-131.

Li, Fengliang (2016) Economies of scale and scope in internationalisation: Evidence from Chinese universities, China: An International Journal, 14(2), 189-200. 
Longlong, Hou, Li Fengliang and Min Weifang (2009) Multiproduct total cost functions for higher education: the case of Chinese research universities, Economics of Education Review, $28,505-511$.

Mamun, Shamsul Arifeen Khan (2011) Are public universities of Bangladesh cost efficient? An empirical evidence, South Asia Economic Journal, 12(2), 221-237.

Marisha, Sumit Kumar Banshal and Vivek Kumar Singh (2017) Research performance of central universities in India, Current Science, 112(11), 2198-2207.

Manuel, Thomas (2018) Indian university rankings internally inconsistent, Nature Index, 9 April, https://www.natureindex.com/news-blog/indian-university-rankings-inherentlyinconsistent, accessed 3 July 2019.

McMahon, Walter W. (1998) Education and growth in East Asia, Economics of Education Review, 17(2), 159-172.

Sachs, Jeffrey D. (2012) From Millennium Development Goals to Sustainable Development Goals, The Lancet, 379, 2206-2211.

Sahney, Sangeeta and Jitesh Thakkar (2016) A comparative assessment of performance of select higher education institutes in India, Quality Assurance in Education, 24, 278-302.

Sharma, G.D. (1980) Institutional Costs of University Education: a Study of Costs and Efficiency of Indian University System, New Delhi: Research Cell in Economics of Education, Association of Indian Universities.

Tilak, Jandhyala (1988) Costs of education in India, International Journal of Educational Development, 8, 25-42.

Tyagi, Preeti, Shiv Prasad Yadav and S.P. Singh (2009) Relative performance of academic departments using DEA with sensitivity analysis, Evaluation and Program Planning, 32, 168177.

Verry, Donald and Richard Layard (1975) Cost functions for university teaching and research, Economic Journal 85, 55-74.

Verry, Donald and Bleddyn Davies (1976) University Costs and Output, Amsterdam: Elsevier.

Zhang, Liang-Cheng and Andrew C. Worthington (2018) Explaining estimated economies of scale and scope in higher education: a meta-regression analysis, Research in Higher Education, 59(2), 156-173. 


\section{APPENDIX}

Table A1: Variables included in the NIRF rankings 2019

\begin{tabular}{|c|c|}
\hline HEI activity: & Reflected by variables: \\
\hline $\begin{array}{l}\text { Teaching, Learning \& Resources (TLR) } \\
\text { Weighting }=0.3\end{array}$ & $\begin{array}{l}\text { Student Strength including Doctoral } \\
\text { Students (SS) } \\
\text { Faculty-student ratio with emphasis on } \\
\text { permanent faculty (FSR) } \\
\text { Combined metric for Faculty with PhD (or } \\
\text { equivalent) and Experience (FQE) } \\
\text { Financial Resources and their Utilisation } \\
\text { (FRU) }\end{array}$ \\
\hline $\begin{array}{l}\text { Research and Professional Practice (RP) } \\
\text { Weighting }=0.3\end{array}$ & $\begin{array}{l}\text { Combined metric for Publications (PU) } \\
\text { Combined metric for Quality of Publications } \\
\text { (QP) } \\
\text { IPR and Patents: Published and Granted } \\
\text { (IPR) } \\
\text { Footprint of Projects and Professional } \\
\text { Practice (FPPP) }\end{array}$ \\
\hline $\begin{array}{l}\text { Graduation Outcomes (GO) } \\
\text { Weighting }=0.2\end{array}$ & $\begin{array}{l}\text { Metric for University Examinations (GUE) } \\
\text { Metric for Number of Ph.D. Students } \\
\text { Graduated (GPHD) }\end{array}$ \\
\hline $\begin{array}{l}\text { Outreach and Inclusivity (OI) } \\
\text { Weighting }=0.1\end{array}$ & $\begin{array}{l}\text { Percentage of Students from Other } \\
\text { States/Countries (Region Diversity RD) } \\
\text { Percentage of Women (Women Diversity } \\
\text { WD) } \\
\text { Economically and Socially Challenged } \\
\text { Students (ESCS) } \\
\text { Facilities for Physically Challenged Students } \\
\text { (PCS) } \\
\text { Perception (PR) Ranking }\end{array}$ \\
\hline $\begin{array}{l}\text { Peer Perception } \\
\text { Weighting }=0.1\end{array}$ & Academic Peers and Employers (PR) \\
\hline
\end{tabular}

Source: https://www.nirfindia.org/2019/Ranking2019.html 